\title{
LITERATURA E MUDANÇA: TEORIA E SOCIEDADE NA SEGUNDA METADE DO SÉCULO XX
}

\author{
Hugo Langone \\ Mestrando em Teoria da Literatura - UFRJ
}

\begin{abstract}
Resumo: A partir da segunda metade do século XX, os estudos literários foram tomados por diversas concepções da relação entre literatura e sociedade, esquivando-se das visões que colocavam a obra de arte como um objeto isolado. Filiados a diferentes correntes de pensamento, muitos foram os autores que se aventuraram a analisar a dimensão política da ficção. Através de um recorte que passa por teóricos como T. S. Eliot, Jacques Ranciére, Theodor Adorno, Gilles Deleuze e Wolfgang Iser, este artigo procura apresentar os pontos de convergência e distanciamento entre os pensadores, revelando a complexidade deste rico terreno.
\end{abstract}

Palavras-chave: Teoria literária; Sociedade; Pluralidade; Século XX.

\begin{abstract}
From the half of the 20th century on, literary studies were flooded by several conceptions of the relation between literature and society, deviating from the views that used to conceive art as an isolated object. Affiliated to different chains of thought, a high number of authors ventured themselves into the task of analyzing the political dimension of fiction. Focusing on thinkers such as T. S. Eliot, Jacques Ranciére, Theodor Adorno, Gilles Deleuze and Wolfgang Iser, this article aims at presenting the points of convergence and separation between the authors, revealing the complexity of this rich subject.
\end{abstract}

Keywords: Theory of literature; Society; Plurality; 20th century. 
Falar em literatura e sociedade, hoje, pode dar a impressão de se abordar temas e conceitos ultrapassados. A relação dos dois termos pode comumente remeter a uma arte apenas panfletária, pobre em reflexão e, principalmente, pobre em seu trabalho lingüístico, em sua modelagem da linguagem comum. No entanto, essa tendência de julgamento não é antiga, e parece ter ganhado um grande fôlego com o início do século XX, quando a teoria da literatura viu nascerem tendências de análise textuais que buscavam concentrar-se apenas na lógica interna e na estruturação do trabalho, em detrimento de sua função e posição social.

Aristóteles, por exemplo, ao descrever no século IV a.C as formas poéticas da Grécia antiga, já demonstrava a relação intrínseca entre o trabalho artístico e a organização social, principalmente ao descrever a existência de diferentes representações do homem em cada gênero poético:

Essas diversidades podem ocorrer igualmente na arte da dança, na da flauta ou da cítara; bem assim no que tange à prosa e na poesia não musicada. Homero, por exemplo, imitava pessoas superiores; Cleofonte, iguais; Hegêmon de Tasos, o primeiro a compor paródias, e Nicócares, o autor da Dilíada, inferiores; o mesmo se diga quanto aos ditirambos e nomos; podem-se criar caracteres como os ciclopes de Timóteo e de Filóxeno.

Nessa mesma diferença divergem a tragédia e a comédia; esta os quer imitar inferiores, e aquela, superiores aos da atualidade. ${ }^{1}$

Escrevendo o que poderia ter sido, a poesia então "encerra verdades gerais", e “enunciar verdades gerais é dizer que espécie de coisas um indivíduo de natureza tal vem a dizer ou fazer verossímil ou necessariamente" ${ }^{2}$.

Outro exemplo da Antigüidade pode ser encontrado em uma obra da maturidade de Horácio, elaborada três séculos após o texto de Aristóteles. Sua Epistola ad Pisones, mais conhecida como Ars Poetica, também exemplifica, talvez de forma até mais precisa do que o filósofo grego, o impacto quase imediato causado pela obra de arte. Vejamos como o autor latino mostra como a comédia antiga precisou ser repreendida legalmente, pela influência que seu conteúdo exercia:

A esses seguiu a comédia antiga, não sem muito aplauso: mas a liberdade descambou num excesso e violência [uitium libertas], que pedia repressão legal:

\footnotetext{
${ }^{1} 2005$, II, p. 20.

${ }^{2}$ Ibid., IX, p. 28.
} 
aprovou-se uma lei e, tolhido o direito de fazer mal, o coro calou-se ignobilmente. $^{3}$

Ironicamente, parece que principalmente na primeira metade do século XX essa consciência do impacto e da potencialidade social da poesia ficou a cargo dos grandes ditadores. Enquanto os críticos se concentravam no texto como unidade isolada, líderes como Lênin, Stalin e Hitler percebiam os perigos que a produção artística representava à manutenção do governo, e não mediam esforços para que fossem eliminadas completamente.

Aos poucos, contudo, foram sendo retomadas as discussões em torno da relação entre poesia e sociedade, e na segunda metade do século XX o debate ganhou ainda mais força, à medida que surgia uma quantidade ainda maior de reflexões. São inúmeros os teóricos e poetas que se aventuraram a analisar essa complexa interseção, e é impossível trabalhar todos a fundo, como merecem. No entanto, um pequeno esforço, na difícil seleção de alguns nomes, pode servir como uma breve introdução à complexidade desse terreno.

Em 1943, T.S. Eliot foi ao British-Norwegian Institute apresentar suas visões sobre a "Função Social da Poesia". O texto, que hoje está na lista das produções mais famosas do poeta, foi incluído no livro On Poetry and Poets, e só chegou às mãos do público em 1957.

Ao se propor a abordar a relação entre poesia e sociedade, Eliot de início se vê obrigado a afirmar que a função social do poeta se distingue da relação que o receptor tem com a o texto. Para ele, na poesia o leitor recebe claramente

a comunicação de uma nova experiência, algum entendimento novo do familiar, ou a expressão de algo que vivenciamos mas não conseguimos descrever em palavras, que amplia nossa consciência ou aperfeiçoa a nossa sensibilidade. ${ }^{4}$

No entanto, Eliot se coloca a trabalhar o impacto social do que para ele é o verdadeiro compromisso do poeta, o compromisso que, em longo prazo, toca até aqueles que não o lêem: o compromisso com a linguagem. É essa relação do poeta com seu instrumento de trabalho que preserva a língua, a amplia e a melhora. Visão semelhante

\footnotetext{
${ }^{3} 2005$, p. 63 .

${ }^{4} 1969$, p. 18.
} 
havia sido apresentada por Ezra Pound na década anterior, quando afirmou que "os bons escritores são aqueles que mantêm a linguagem eficiente"

Em Eliot, a preservação da linguagem está intimamente ligada à preservação da própria tradição poética. Escrever poesia se torna um ato de resgate, de mostrar à comunidade os grandes mestres locais do passado, que escreveram na língua em que cada membro daquele lugar sente e expressa o mundo. A própria produção poética de Eliot ratifica "a sua crença de que a poesia é, basicamente, um 'fenômeno de cultura', um continuum destinado a preservar e reviver a herança legada pelos estratos literários de épocas históricas anteriores" (JUNQUEIRA, 2006, p. 22). Mais do que expor uma imagem de pedantismo, como exageradamente são classificadas, as notas de seu Waste Land são o lado prático dessa convicção. É através desse raciocínio que o próprio poeta pode afirmar, num ensaio posterior, que "ler Milton é certificar-se sobre a genialidade de Spenser" (1969, p. 58). Por essa razão, poucas coisas deveriam ser mais temidas do que o declínio da produção poética de qualquer região, pois

\footnotetext{
a menos que [as pessoas] continuem produzindo grandes autores, e, principalmente, grandes poetas, sua linguagem se deteriorará, sua cultura se deteriorará, e talvez seja absorvida por uma cultura mais forte. [...] Se não tivermos literatura viva, ficaremos cada vez mais alienados da literatura do passado; a menos que mantenhamos a continuidade, nossa literatura do passado se tornará cada vez mais remota, até que ficará mais estranha para a gente como a literatura de um povo estrangeiro. (Ibid., p. 21)
}

Ao fincar suas raízes na tradição, o poeta então se torna responsável pela história de seu povo, tanto da história passada quanto da história que está para ser construída. Afinal, ao tomar posse da linguagem, ele amplia o seu significado, para que cada vez mais possa expressar os sentimentos da comunidade.

Esse desenvolvimento da matéria-prima do poeta, por sua vez, não é fácil de ser mapeado, e muito menos de ser previsto. A percepção de uma linguagem que, ao revelar a tradição, também aponta para sua própria ampliação não é massiva. Para Eliot, qualquer poeta, antes de ser aclamado, fala com um pequeno corpo de leitores que estão à frente de seu tempo, e que se perpetuam de geração em geração. São esses leitores que gradualmente inserem essa "nova sensibilidade" na linguagem corriqueira, até que ela faça parte do senso comum, da expressão natural de uma comunidade.

\footnotetext{
${ }^{5} 2006$, p. 36.
} 
Quase quinze anos após Eliot ter ministrado sua palestra sobre "A Função Social da Poesia", Theodor Adorno se enveredou por caminhos diferentes ao falar sobre a função social que ganhava a lírica feita na sociedade industrializada. Para o filósofo alemão, os tempos modernos não eram os mais animadores, e provavelmente não o seriam os tempos atuais, caso exista alguma diferença drástica entre a sociedade que ele denunciava e a nossa. Em parceria com Horkheimer, ele descreveu a forma artística característica de sua época:

\begin{abstract}
[Os produtos] São feitos de tal forma que sua apreensão adequada exige, é verdade, presteza, dom de observação, conhecimentos específicos, mas também de tal sorte que proíbem a atividade intelectual do espectador, se ele não quiser perder os fatos que desfilam velozmente diante de seus olhos. O esforço, contudo, está tão profundamente inculcado que não precisa ser atualizado em cada caso para recalcar a imaginação. Quem está tão absorvido pelo universo do filme - pelos gestos, imagens e palavras - , que não precisa lhe acrescentar aquilo que fez dele um universo, não precisa necessariamente estar inteiramente dominado no momento da exibição pelos efeitos particulares dessa maquinaria. Os outros filmes e produtos culturais que deve obrigatoriamente conhecer tornaram-no tão familiarizado com os desempenhos exigidos da atenção, que estes têm lugar automaticamente. [...] Os produtos da indústria cultural podem ter a certeza de que até mesmo os distraídos vão consumi-los atentamente. Cada qual é um modelo da gigantesca maquinaria econômica que, desde o início, não dá folga a ninguém, tanto no trabalho, quanto no descanso, que tanto se assemelha ao trabalho. ${ }^{6}$
\end{abstract}

Não é surpreendente, então, que para Adorno a lírica tenha que se organizar de modo a fugir da sua própria reificação, como resistência ao processo de deteriorização artística provocado pela indústria cultural. A lírica se torna, assim, a "depositária privilegiada da utopia e da crítica do existente" ${ }^{\text {"7 }}$.

Foi na tendência anti-realista que Adorno encontrou a maior expressão dessa literatura ideal. Para ele, o distanciamento buscado pelos autores dessa corrente já era uma denúncia pura da subordinação das formas artísticas aos interesses econômicos, da "coisificação do mundo", da "dominação das mercadorias sobre os homens, que se propagou desde a Era Moderna e que, desde a Revolução Industrial, desdobrou-se em força dominante da vida" ${ }^{8}$. Produzir algo que "fugia" ao real era proclamar a decadência desse real.

\footnotetext{
${ }^{6} 1985$, p. 119.

${ }^{7}$ Berardinelli, 2007, p. 33.

8 2003, p. 69.
} 
Porém, como explicar a força de uma poesia que toma distância do existente? Como ela poderia sugerir qualquer mudança do real ao se obscurecer nessa elevação? A resposta é dada pelo próprio Adorno:

\begin{abstract}
Não que aquilo que o poema exprime tenha de ser imediatamente aquilo que todos vivenciam. Sua universalidade não é uma volonté de tous, não é a da mera comunicação daquilo que os outros simplesmente não são capazes de comunicar. Ao contrário, o mergulho no individuado eleva o poema lírico ao universal por tornar manifesto algo de não distorcido, de não captado, de ainda não subsumido, anunciando desse modo, por antecipação, algo de um estado em que nenhum universal ruim, ou seja, no fundo algo particular, acorrente o outro, o universal humano. (Ibid., p. 66)
\end{abstract}

Assim, para o filósofo alemão a fuga do real por parte da lírica não é uma elevação, mas uma submersão estetizante na mais pura individuação, que encontra nesta catábase a expressão mais alta do universal, a interseção entre todos os homens, a expressão livre de qualquer ideologia, que transcende o social que a própria poesia obedece.

Curiosamente, assim como para T. S Eliot o movimento inicial para que o trabalho do poeta chegue à comunidade deve passar primeiro por uma èlite, também para Adorno a

subjetividade poética deve sua existência ao privilégio: somente a pouquíssimos homens, devido às pressões da sobrevivência, foi dado apreender o universal no mergulho em si mesmos, ou foi permitido que se desenvolvessem como sujeitos autônomos, capazes de se expressar livremente. ${ }^{9}$

Também é curioso como os caminhos evitados pelo poeta de língua inglesa ganham importâncias diferentes em outros autores. Analisemos as posições de Jacques Rancière sobre estética e política, por exemplo.

Como vimos, Eliot toma "a comunicação de uma nova experiência, algum entendimento novo do familiar, ou a expressão de algo que vivenciamos, mas não conseguimos descrever em palavras" ${ }^{\prime \prime}$, como extensão individual da poesia, que caracterizaria sua essência mais básica. Para ele, sua potência social não poderia ser

\footnotetext{
${ }^{9}$ Ibid., p. 76.

${ }^{10} 1969$, p. 18.
} 
julgada por esse impacto, que seria singular. Em Ranciére, entretanto, essa possibilidade de reconfiguração do real é onde se deposita a potencialidade política da obra.

Enquanto para Walter Benjamin, envolto pelos terrores do nazismo, a "estetização da política"11 só poderia ter como finalidade a guerra, pois somente ela permitiria "dar um objetivo aos grandes movimentos de massa, preservando as relações de produção existentes ${ }^{12}$, a expressão ganha, no teórico francês, um sentido outro, que abriria as portas para qualquer possibilidade de modificação por parte da estética:

\begin{abstract}
Essa estética não deve ser entendida no sentido de uma captura perversa da política por uma vontade de arte, pelo pensamento do povo como obra de arte. Insistindo na analogia, pode-se entendê-la num sentido kantiano eventualmente revisitado por Foucault - como o sistema das formas a priori determinando o que se dá a sentir. É um recorte dos tempos e dos espaços, do visível e do invisível, da palavra e do ruído que define ao mesmo tempo o lugar e o que está em jogo na política como forma de experiência. ${ }^{13}$
\end{abstract}

Assim, a literatura seria especialmente responsável por um recorte do comum, das suas competências, das suas relações temporais e espaciais, das características desse espaço que tornam algo ou alguém visível ou invisível - e talvez poucas coisas exemplifiquem mais esse aspecto do literário do que Baudelaire afirmando que "há certas sensações deliciosas cujas impressões não excluem a intensidade" e que "não há ponta mais aguda do que o infinito", "14 ou Drummond denunciando seu "tempo de divisas,/ tempo de gente cortada" 15 .

É através dessa estética comum, então, que devem ser analisadas as práticas estéticas propriamente ditas. E são essas práticas estéticas que desempenham o papel político da arte, e, mais especificamente, da arte das palavras, a poesia. Porque para Rancière a escrita "destrói todo fundamento legítimo da circulação da palavra, da relação entre os efeitos da palavra e as posições dos corpos no espaço comum" ${ }^{\text {"16 }}$.

A prática estética assim elabora, quando lhe é permitida tal liberdade, uma pluralidade de mundos sensíveis, alternativas para os que estão engendrados por aquela organização comum que serve como base para o pensamento do teórico, e a produção literária, de forma especial, se aproxima mais ainda do enunciado político, pois ambas

\footnotetext{
11 1994, p. 195.

${ }^{12}$ Id., ibid. .

${ }^{13} 2005$, p. 16.

14 2006, p. 23.

15 2006, p. 161.

16 2005, p. 17.
} 
traçam mapas do visível, , trajetórias entre o visível e o dizível, relações entre modos do ser, modos do fazer e modos do dizer. Definem variações das intensidades sensíveis, das percepções e capacidades dos corpos. Assim se apropriam dos humanos quaisquer, cavam distâncias, abrem derivações, modificam as maneiras. [...] Reconfiguram o mapa do sensível confundindo a funcionalidade dos gestos e dos ritmos adaptados aos ciclos naturais da produção, reprodução e submissão. O homem é um animal político porque é um animal literário [...]. ${ }^{17}$

A arte, ao se aproximar da vida, se poetiza. E a vida, ao ser tocada pela arte, se amplia.

A literatura como forma de possibilidades do real também foi o caminho escolhido por Gilles Deleuze, que tratou o tema discretamente, mas nem por isso com menos ênfase e profundidade.

Fugindo de uma concepção aristotélica da arte, que vê o artista como aquele que dá forma ao informe, Deleuze trabalha o escritor como o homem que foge da condiçãoHomem, "expressão dominante que pretende impor-se a toda matéria"18. Escrever seria fugir a esse padrão, fuga que não se caracteriza pela assunção de uma forma, mas pelo posicionamento em uma zona de vizinhança, de indiscernibilidade. Assim, "a escrita é inseparável do devir: ao escrever, estamos num devir-mulher, num devir-animal ou vegetal, num devir-molécula, até num devir imperceptível"19.

Semelhante ao processo de individuação apontado por Adorno, em Deleuze o ato individual do devir também se estende e se instala no social, mas não através da projeção de um eu: ele se eleva num indefinido. A passagem de Deleuze é belíssima, e merece transcrição:

Mas a literatura segue a via inversa, e só se instala descobrindo sob as aparentes pessoas a potência de um impessoal, que de modo algum é uma generalidade, mas uma singularidade no mais alto grau: um homem, uma mulher, um animal, um ventre, uma criança... As duas primeiras pessoas do singular não servem de condição à enunciação literária; a literatura só começa quando nasce em nós uma terceira pessoa que nos destitui do poder de dizer Eu (o "neutro" de Blanchot). ${ }^{20}$

\footnotetext{
${ }^{17}$ Ibid., p. 59.

${ }^{18}$ Deleuze, 1997, p. 11.

${ }^{19}$ Id., ibid.

${ }^{20}$ Ibid., p. 13.
} 
Na eliminação do eu, o escritor se compromete com a invenção de um povo, ele faz emergir de si uma sociedade, que está enterrada no delírio do que só ele viu e ouviu, pois "a literatura é delírio", e "não há delírio que não passe pelos povos, pelas raças e tribos" 21 .

E como Eliot, Deleuze também considera as possibilidades de modificação lingüística que a literatura encerra. Curiosamente, entretanto, essa atuação da arte literária, para o filósofo francês, é de maior visibilidade. Nele a literatura cria uma língua estrangeira, redescobre um dialeto, mas não antes sem abraçar sua própria língua, criando uma reviravolta, levando ao limite a expressão comum.

Se, como não pretende esconder, Deleuze tira essas suas conclusões a partir de autores como Proust, Kafka e Melville, Wolfgang Iser, para desenvolver sua teoria do ficcional e, a partir dela, propor uma influência literária no social, resgata uma longa linhagem de filósofos que, como aponta Costa Lima, deram um "estatuto precário" à ficção ${ }^{22}$. Desconstruindo essa tradição, inaugurada na Antigüidade e perpetuada até as décadas mais recentes, Iser oferece uma nova configuração das relações entre o ficcional, a realidade e o imaginário.

Para o teórico alemão, o grande do problema das teorias ficcionais clássicas é a oposição que fazem entre real e ficcional. Mesmo quando o fingere é trabalhado como uma característica humana natural, em Jeremy Bentham e Hans Vaihinger, por exemplo, suas conseqüências não são levadas a fundo. Vejamos como Karlheinze Stierle, que tem em Iser "a resposta decisiva" para a questão da ficção ${ }^{23}$, aponta a boa-nova anunciada pelo alemão:

Contudo, enquanto no entendimento tradicional o fictício era tomado como conceito contrário ao real e a ficção como contrária à realidade, Iser vê o fictício como parceiro do imaginário e a ambos compreende como momentos de transgressão do real. ${ }^{24}$

Iser desmembra o binômio ficção-realidade e insere o ato de fingimento, isto é, o fictício, entre um índice do real e o imaginário, que, como mostraram Coleridge, Sartre e Castoriadis, "precisa ser mobilizada por algo externo, [...] não possui intencionalidade, é antes por esta imantado, pelo uso que dele é feito em cada caso" ${ }^{, 25}$.

\footnotetext{
${ }^{21}$ Ibid., p. 15.

${ }^{22} 2006$, p. 260

23 2006, p. 9.

${ }^{24}$ Id., ibid.

${ }^{25}$ Iser, 1996, p. 259.
} 
A literatura, quando se dilui no fingere que lhe é característico, se torna o elemento de ativação do imaginário, a única possibilidade de tocá-lo. Fingir é elevar e metamorfosear o real, ao mesmo tempo em que tange a instância imaginária; o fingere não se torna, em Iser, o pólo oposto à realidade, mas a engloba, a transforma e a transcende ${ }^{26}$.

É nesta transcendência, então, que em Iser se encontra a potencialidade social da literatura. Para ele, sobre o pacto que o leitor faz com o texto paira um imaginário que, enquanto singular, também é condicionado socialmente. Esse condicionamento social do imaginário é um dos fatores que, a nosso ver, permite à literatura que se reconstrua, que seja lida de diferentes formas em diferentes tempos, pois a moldura imaginária muda de pessoa para pessoa, de sociedade para sociedade e de tempos para tempos. E, quando o leitor se depara com um texto que ativa profundamente seu imaginário, ele também o tem modificado, the permitindo a ampliação de novos modelos. E de fato se torna ainda mais intrigante esse condicionamento do imaginário social quando percebemos, por exemplo, a importância de grandes clássicos na formação de uma cultura, como acontece com Dante, Homero, Cervantes, Ovídio, Virgílio e Shakespeare, que podem ser mapeados em Calvino, Borges e em uma série interminável de autores contemporâneos.

Ao contrário de uma certa convicção que parece ter sido criada pelo senso comum acadêmico, a relação entre literatura e sociedade não pode, em hipótese nenhuma, ser reduzida à simplicidade de uma literatura que é apenas engajada politicamente. A potência social da verdadeira obra literária está enraizada em sua própria essência, e a lufada de ar que a discussão ganhou na segunda metade do século passado e no início desta década não deixa dúvidas disso.

A inquietação provocada pela função política da literatura ganhou uma extensão tão grande que atingiu pensadores com heranças teóricas totalmente diversas. T.S Eliot era cristão declarado; Adorno e Rancière perpetuaram uma tradição marxista; Deleuze bebia na filosofia continental de Nietzsche e no racionalismo de Spinoza; Wolfgang Iser se opôs ao formalismo e, junto com seus companheiros alemães na escola de Constance, propagou o modelo construtivista da estética da recepção.

Através desse pequeno e despretensioso recorte de teóricos, pode-se perceber as diversas veredas que esse vasto terreno pode tomar, o que desde o início foi o grande

\footnotetext{
${ }^{26}$ Talvez seja importante frisar que a literatura, para Iser, se destaca dos outros discursos fictícios por possuir constituições muito peculiares. A arte literária, além da seleção de seu tópico e do entrelaçamento lingüístico, tem a capacidade de se desnudar, de se mostrar fictícia, de se assumir descompromissada com qualquer representação de real. Ela, mais do que qualquer outro modelo, assume o caráter de jogo entre a obra e o leitor, que pactua e aceita o texto.
} 
objetivo deste pequeno trabalho. A discussão é ampla, árdua, nuançada e, ao mesmo tempo, fascinante. Ela toma diversas formas, e cada uma delas nos enche de interrogações e motivações, demandando um deslocamento de pressupostos que altera completamente o resultado de análise - deslocamento que, para o crítico, também se caracteriza como um posicionamento político. Certamente, diante desse mundo de possibilidades, é difícil entender como, por tanto tempo, essa discussão foi empurrada para as margens dos debates teóricos.

\section{Referências}

ADORNO, Theodor W. "Palestra sobre lírica e sociedade". In: Notas de literatura I. Tradução de Jorge de Almeida. São Paulo: Duas Cidades; Ed. 34, 2003.

.; HORKHEIMER, Max. "A indústria cultural: o esclarecimento como mistificação das massas”. In: Dialética do esclarecimento. Tradução de Guido Antonio de Almeida. Rio de Janeiro: Jorge Zahar Ed., 1985.

ANDRADE, Carlos Drummond de. Antologia poética. Rio de Janeiro: Record, 2006.

ARISTÓTELES. “Arte poética”. In: A poética clássica. Tradução de Jaime Bruna. São Paulo: Cultrix, 2005.

BAUDELAIRE, Charles. Pequenos poemas em prosa. Tradução de Ivo Barroso. Rio de Janeiro: Record, 2006.

BENJAMIN, Walter. “A obra de arte na era de sua reprodutibilidade técnica”. In: Magia e técnica, arte e politica: ensaios sobre literatura e história da cultura. Tradução de Sérgio Paulo Rouanet. São Paulo: Brasiliense, 1994.

BERARDINELLI, Alfonso. “As muitas vozes da poesia moderna”. In: Da poesia à prosa. Tradução de Maurício Santana Dias. São Paulo: CosacNaify, 2007.

DELEUZE, Gilles. "A literatura e a vida”. In: Crítica e clínica. Tradução de Peter Pál Pelbart. São Paulo: Ed. 34, 1997.

ELIOT, T. S. On Poetry and Poets. Londres: Faber and Faber Ltd., 1969.

HORÁCIO. "De arte poetica”. Texto em latim. In: BRINK, C. O. Horace on Poetry: The “Ars Poetica”. Cambridge: Cambridge University Press, 1971. . "Arte poética”. In: A poética clássica. Tradução de Jaime Bruna. São Paulo:

Cultrix, 2005. 
ISER, Wolfgang. O fictício e o imaginário: perspectivas de uma antropologia literária. Tradução de Johannes Kretschmer. Rio de Janeiro: EdUERJ, 1996.

JUNQUEIRA, Ivan. "Eliot e a poética do fragmento". In: ELIOT, T. S. Poesia. Rio de Janeiro: Nova Fronteira, 2006.

LIMA, Luiz Costa. História. Ficção. Literatura. São Paulo: Companhia das Letras, 2006.

POUND, Ezra. $A B C$ da literatura. Tradução de Augusto de Campos e José Paulo Paes. São Paulo: Cultrix, 2006.

RANCIÉRE, Jacques. A partilha do sensível: estética e política. Tradução de Mônica Costa Netto. São Paulo: EXO experimental org.; Ed. 34, 2005.

STIERLE, Karlheinz. A ficção. Tradução de Luiz Costa Lima. Rio de Janeiro: Caetés, 2006. 